\title{
DEVELOPMENT OF A CITSCI AND ARTIFICIAL INTELLIGENCE SUPPORTED GIS PLATFORM FOR LANDSLIDE DATA COLLECTION
}

\author{
Recep Can ${ }^{1}$, Sultan Kocaman ${ }^{1, *}$, Candan Gokceoglu ${ }^{2}$ \\ ${ }^{1}$ Hacettepe University, Dept. of Geomatics Engineering, 06800 Beytepe Ankara, Turkey - (recepcan, \\ sultankocaman)@ hacettepe.edu.tr \\ ${ }^{2}$ Hacettepe University, Dept. of Geological Engineering, 06800 Beytepe Ankara, Turkey - cgokce@ hacettepe.edu.tr
}

Commission V, WG V/3

KEY WORDS: WebGIS, Citizen Science, Deep Learning, Landslide, Data Quality, CNN

\begin{abstract}
:
Geospatial data are fundamental to understand the relationship between the geographical events and the Earth dynamics. Although the geospatial technologies aid geodata collection, the increasing possibilities yield new application areas and cause even a greater demand. Considering the increment in data quantity and diversity, to be able to work with the data, they must be collected, stored, analysed and presented with the help of specifically designed platforms. Geographical Information Systems (GIS) with mobile and web support are the most suitable platforms for these purposes. On the other hand, the location-enabled mobile, web and geospatial technologies empowered the rise of the citizen science (CitSci) projects. With the CitSci, mobile GIS platforms enable the data to be collected from almost any location. As the size of the collected data increases, considering automatic control of the data quality has become a necessity. Integrating artificial intelligence (AI) with the CitSci based GIS designs allows automatic quality control of the data and helps eliminating data validation problem in CitSci. For this reason, the purpose of the present study is to develop a CitSci and AI supported GIS platform for landslide data collection because landslide hazard mitigation efforts require landslide susceptibility, hazard and risk assessments. Especially, landslide hazard assessments are necessary the time of occurrence of a landslide. Although this information is crucial, it is almost impossible to collect time of occurrence in regional hazard assessment efforts. Consequently, use of CitSci for this purpose may provide valuable information for landslide hazard assessments.
\end{abstract}

\section{INTRODUCTION}

Natural hazards are observed throughout the world. As stated by Cutter et al. (2015), the yearly economic losses from geophysical, hydro-meteorological and climatological events could exceed US $\$ 300$ billion by 2030 worldwide; and more lives and assets can be under risk due to climate change, globalization, technological change, urbanization and political and economic instability. In order to fight the problems of today, new approaches need to be developed and put into practice.

To understand the Earth dynamics and related spatial events, geospatial data has crucial importance. Geospatial data enable collaborations between different scientific disciplines and contribute to them by adding new horizons. In order to facilitate interdisciplinary work, geospatial data must be obtained first; and stored, analysed and presented on a suitable platform. Geographical Information Systems (GIS), which can be defined as "Organized activity by which people measure and represent geographic phenomena then transform these representations into other forms while interacting with social structures" (Chrisman, 1999), are the most appropriate platforms for this purpose. A GIS design must cover the proper data collection approaches, spatial analysis methods for conversions and interpretation, and also the most suitable presentation approaches for sound and vibrant interaction with the social structures.

The geodata can be collected by using sensors solely (i.e. IoT) or by people possibly with the help of sensors and online platforms. When the data are collected by people, some sort of interpretation can also be included at the beginning of the process via selective sampling. As volunteer-based or crowdsourcing-based approaches, Volunteered Geographical Information (VGI) and Citizen Science (CitSci) can also be used for the collection and interpretation of geodata at different contribution levels. CitSci refers to the participation of volunteers in scientific processes regardless their scientific, technical or research background. Oxford English Dictionary defines CitSci as: "Scientific work undertaken by members of the general public, often in collaboration with or under the direction of professional scientists and scientific institutions." (CSA, 2020). For different definitions and further discussion on participatory science, please see Brovelli et al. (2020). Owing to the developments in Information and Communication Technologies (ICT), nearly every location is reachable nowadays, and online CitSci repositories, where geospatial data are collected, analysed and reported, are good options to benefit the CitSci potential.

\footnotetext{
* Corresponding author
} 
CitSci has also critical importance for geoscience researches since it allows the collection of massive amounts of timely geospatial data. GeoCitSci.com, a CitSci platform for geoscience researches, has been initiated at Hacettepe University as a collaboration between the Departments of Geomatics Engineering and Geological Engineering. A CitSci and artificial intelligence (AI) supported WebGIS platform was designed and implemented in this study to contribute to landslide researchers. The platform consists of a WebGIS application for data collection and presentation, a mobile app (LaMA) for data provision, and both have AI system to control processes for ensuring data quality.

The platform aims to collect volunteers' observations about landslides together with images, location and time of occurrence information. To collect the observations efficiently, the system was designed as simple as possible so that any volunteer can use it without the need of knowledge or experience related to the topic. In addition to its simple design, the system was developed to be able to work on multiple devices for receiving data from any platform. Data quality control is also very important for the system design for effective utilization of resources and increasing the quality of the results to be obtained from the collected data.

The platform is basically composed of three layers, which are presentation, application and data layer. The presentation layer is responsible for retrieving location and the volunteer observation on the landslide with images, and for showing the image on the map after the data are controlled and classified automatically by a deep learning model. The application layer includes the deep learning model, which is specifically designed and implemented for classifying images with landslides. The application layer controls form data, processes and classifies images, and send them to the data layer in order to upload to the database management system. The data layer is responsible for storing and managing the data.

A CitSci project has several challenges, such as engaging people to contribute to the project through a website. Several parameters should be taken into account when designing a CitSci project. The user interface design is extremely important so that all participants can use the system easily without the need of any prior knowledge or experience. Platform independency and compatibility with multiple devices are also important aspects. Reaching out to more volunteers means collecting more information about the problem. Quality control of the collected data is another aspect to consider while designing a CitSci project. The developed web application and the technologies used in this study addresses all these questions. The detailed system design is described in following sections.

\section{BACKGROUND}

\subsection{CitSci Platforms Apps for Natural Hazards}

CitSci based apps enable the data to be collected where the natural hazard occurred. Many studies have been carried out with the aim of using CitSci platforms in natural hazards. Kocaman et al. (2018) reviewed the CitSci approaches for disaster management efforts.
For example; De Longueville et al. (2010) developed a workflow with the aim of validation VGI data in natural hazards with an example from U.K floods. Schade et al. (2013) explains how VGI sensing techniques help crisis information system and describe a workflow related integration of VGI with the spatial data infrastructures. Nolasco-Javier et al. (2018) have used newspapers, agency reports, interviews and field observations to collect landslide occurrence data in order to derive the rainfall threshold in Philippines. Holderness et al. (2017) have reviewed the Peta Jakarta project, which was a collaboration of university, local government and social networking sites (SNS) for flood mitigation. The purpose of the project was supporting decision makers with the real-time flood situations obtained from the social media.

Liang et al. (2017) have developed CitSci based platform to obtain ground observations during earthquake and integrate available real-time earthquake information with the geospatial data to contribute earthquake science. Cochran et al. (2009) have presented Quake-Catcher Network (QCN) project which aims to increase the number of seismic stations by using volunteers' computing resource as a seismic station to obtain information about large earthquakes through faster and accurate way.

Kocaman and Gokceoglu (2019a) developed the LaMA app for landslide data collection which work on both iOS and Android platforms. Yalcin et al. (2020a) developed an Android app for collecting earthquake intensity data and they produced isointensity map for Istanbul earthquake and also investigated after Elazig earthquake occurred on Jan 24, 2020 in Turkey (Yalcin et al., 2020b). An extensive review on the potential of CitSci for landslide research is given by Kocaman and Gokceoglu (2019b). The Landslide Reporter project of NASA is also an important CitSci initiative that aims to collect landslide related information all over the world (Juang et al., 2019; NASA, 2020).

\subsection{Convolutional Neural Networks in Data Quality Assessment}

The data quality is the major problem for CitSci studies. Crall et al. (2010) studied on improving and integrating data on invasive species collected by citizen scientists and they said that only $39 \%$ of the citizen science programs have any data quality checks in place. In addition, several authors (i.e. Kocaman et al., 2018; Kocaman and Gokceoglu, 2019a, 2019b; Can et al., 2019; Yalcin et al., 2020) mentioned the importance of the quality of data collected by volunteers since it has a direct effect on the accuracy of results. Considering this problem, Yalcin et al. (2020) used the data provided by the trained volunteers. However, it may be difficult or even impossible to train the volunteers if data is collected from all over the world. In this case, various automatic data control systems are needed. Can et al. (2019) developed a Convolutional Neural Network (CNN) based data quality control algorithm proposed to check the landslide photographs provided by the volunteers. 


\section{SYSTEM DESIGN}

The goal of the CitSci supported GIS platforms is collecting geospatial data with the help of volunteers. To collect the data efficiently, the system must be designed as simple as possible so that any volunteers can use it without the need of any knowledge related to topic and experience. In addition to simple design, the system must be developed to be able to work on multiple platforms for receiving data from any device. Data quality assessment is also very important for the system design for effective usage of resources and the quality of the work.

Considering all these requirements, the LaMA app was developed by Kocaman and Gokceoglu (2019a). The app runs across multiple device platforms such as Android, iOS and web. In addition, a web-based data entry possibility was developed in this study for the users who prefer to provide data over a web-browser. Since the technical characteristics of the LaMA app are already provided by Kocaman and Gokceoglu (2019a), only the specifications of the web interface is provided in this paper.

In this section, the system architecture is explained in detail. The overall system design elements are shown in Figure 1. The system is composed of three main layers, which are presentation, application and the data. The presentation layer involves the user interfaces, forms and visualization functionality. The application layer consists of the data processing elements, which are mainly responsible for data and error handling procedures and the quality control system. The data layer is responsible for storing and managing the data, and involves a database management system and file management system. The details on the layers are provided in the following sub-headings.

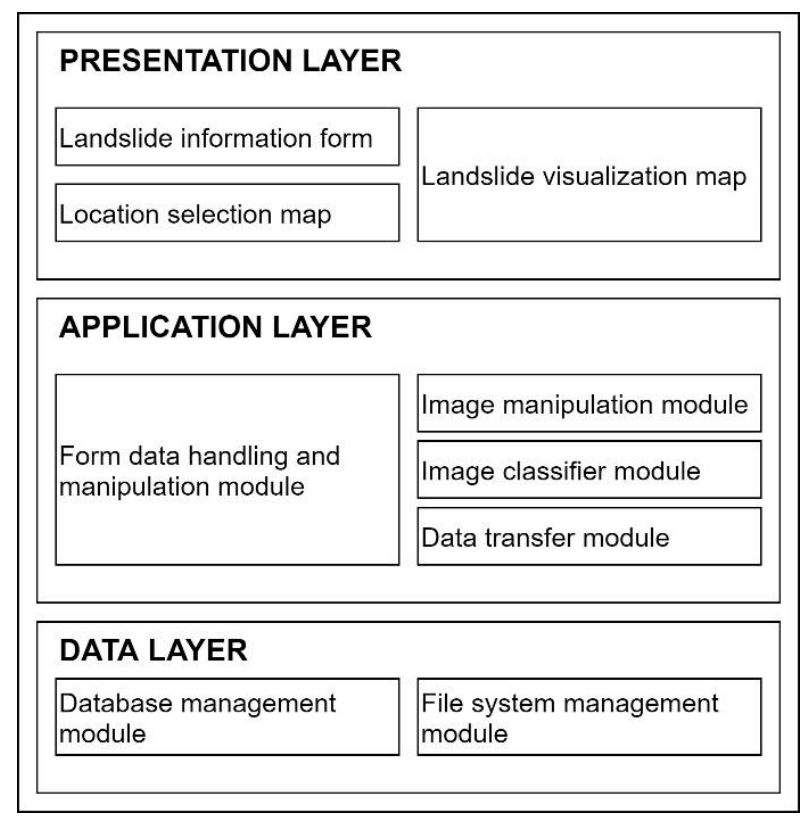

Figure 1. Main components of the developed WebGIS platform (except the mobile app LaMA, which was already presented by Kocaman and Gokceoglu, 2019a).

\subsection{Presentation Layer}

The presentation layer depicted in Figure 1 is responsible for user interactions with the application, so it is the most important part of the application for obtaining the volunteer provided data. This part of the system need to be simple, userfriendly, and compatible with multiple operating systems. The web-based presentation layer is composed of three modules, which are landslide information form, location selection map and landslide visualization map. Homepage of the web interface (Figure 2), the location selection map (Figure 3), and the information provision form (Figure 4) are located in the reporting page.

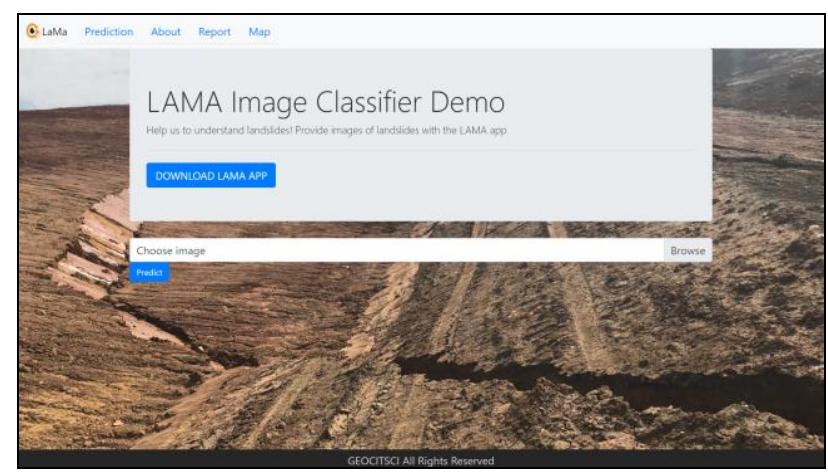

Figure 2. Homepage of the web interface in the presentation layer.

Location selection map allows volunteers send the landslide location along with the landslide photo and additional information by clicking the landslide location on the map (Figure 3). The manual location selection is important for the following situations:

- The user's device has no location feature;

- The user does not know how to enable the location feature on the device;

- The landslide event to be reported may have occurred in an area where user had no Internet access, and wished to send the information later at a location with better accessibility.

Considering these situations, location selection map is included in the reporting page. The location selection map was developed using the open source OpenLayers library (OpenLayers, 2020) together with Bing Maps API (Microsoft, 2020). OpenLayers, a JavaScript library, provides various features that facilitates web mapping application development with high flexibility.

Landslide information form aims to get information and image about landslide. The form has nine data fields, which are username, name, surname, date, latitude, longitude, damage, additional observations on the landslide event, and the image (Figure 4). The latitude and longitude fields cannot be manually edited by the user. They need to be automatically filled by the coordinate values obtained from the location selection map, which triggers the selected point's coordinates on the map. The image part only allows PNG and JPG formatted images. The landslide information form developed using Jinja2, which is a templating language that can be used with Python (for more details, please see Jinja2, 2020). It is 
preferred in this application because it has automatic HTML escaping, which helps preventing XSS attacks; and supports template inheritance. The reporting page is responsive meaning that the application is suitable to work on every device without considering how large or small screen size, mobile or desktop device. The reporting page's interface was developed using Bootstrap 4, which is a front-end component library to be used building responsive web pages (Bootstrap, 2020). Bootstrap makes development faster with its prebuilt components. It is also easily integrated with Openlayers, Jinja2 and Flask.

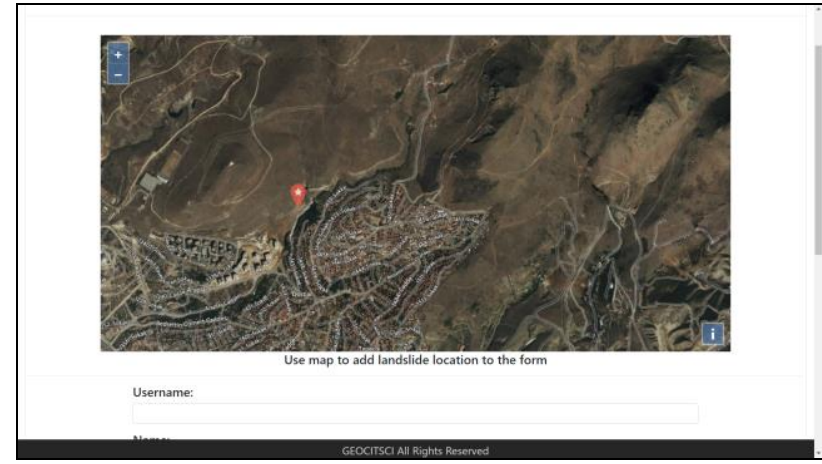

Figure 3. Location selection map on the landslide reporting page.

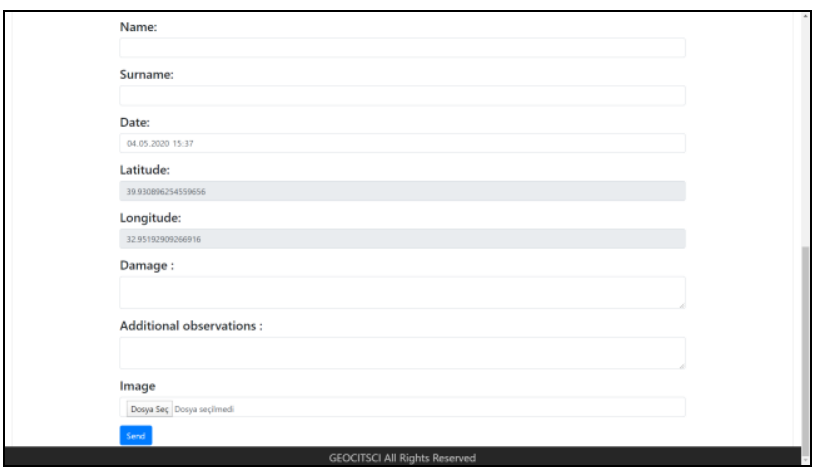

Figure 4. Landslide information form on the landslide reporting page.

The landslide visualization map (Figure 5) aims to show collected landslide photographs via LaMA apps include Android, iOS and Web on the map. Providing feedbacks to the citizen scientists is important for the ensuring their motivation and continuous participation. Visual presentation of the results is thus essential for a GIS-assisted CitSci platform. In addition, visual assessment of the results on a web-map interface can be useful for the quality analysis, such as compliance of the results with actual ground conditions (e.g. compatibility of the landslide data with the lithological characteristics or land use information). Anyone can reach the landslide map by clicking the map tab. The map shows a symbol depicting a landslide event location, which means that a verified landslide image exists for the place. Openlayers and Bootstrap 4 were employed to develop the map interface.

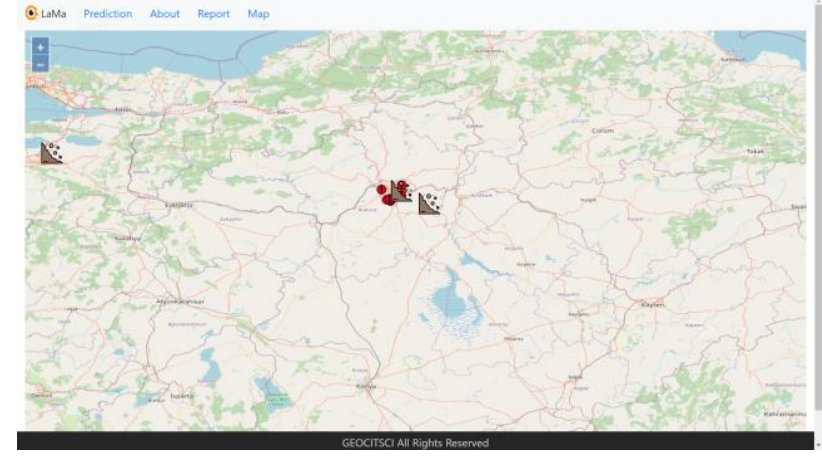

Figure 5. Interface of the web-map application.

\subsection{Application and Data Layers}

The application layer is the backbone of the developed GIS platform. The layer is responsible for the functionality and processes of all platforms including Android, iOS and the web. The layer includes four modules, which are form data handling and manipulation module, image manipulation module, image classifier module and data transfer module. All the modules were implemented with Python 3, and the Flask framework (Flask, 2020) is used to connect the presentation layer and the application layer.

The form data handling and manipulation module is responsible for handling the data provided by the users; and also processing the data so that the data is ready for the data transfer module. First, the module gets the data post by volunteer, and the image in the data is sent to the image manipulation module after it is decoded from bytes. Other data except the image is controlled by the form data handling and manipulation module, and will be sent to the data transfer module if the data can pass all the checks.

The image manipulation module receives and pre-processes the image for the next stage, which applies a quality control using the CNN. The pre-processing steps include aspect aware resizing, radiometric processing, and range normalization. OpenCV, Keras, Tensorflow and PIL are the main libraries used for image manipulation and classification with the inhouse developed modules. Flask is again used for communication between layers.

The image classifier module receives the image data preprocessed by the image manipulation module. Image classifier module is responsible for controlling the image whether the image includes landslide or not. The module has a deep learning model which developed specifically for this purpose, as explained in the following section in detail.

After the classification, the image data and classification results (class labels and their probabilities) are sent to the data transfer module. The data transfer module takes the form data, the image data, and the classification results. The modules rename the image based on the classification results and additional labelling rules, such as processing date and time. The form data, the image path and the prediction result are sent to the database management module and the image is sent to file system management module. Both modules are considered in the data layer. 
The data layer is responsible for storing, writing, reading and querying data. The layer includes two modules, which are the database management module and file system management module. The database management module is responsible for database related works such as database connection, querying, writing etc. The file system management module is responsible for storing the image data.

\subsection{Data Quality Assessment Approach}

The image classifier module has a pre-trained CNN-based deep learning algorithm developed by Can et al. (2019). The module basically evaluates the image posted by the user and classifies the image as irrelevant or landslide. Although four other classes can also be determined with the developed architecture, the developed CitSci platform is only interested in the existence of a landslide event in the photo. Therefore, the other classes are merged with the irrelevant class based on the sum of their probabilities except the landslide class in the image classifier module. If an image includes landslide, the image is stored with corresponding classification result. If not, the image and the information posted with the image are deleted from the memory. This automation reduces storage costs and ensures the efficient use of the storage. Thanks to the deep learning model, manual checks are not required on the obtained data to find out if they are landslide relevant or not. In this way, the cost of the human labour is also eliminated.

Figure 6 represents a simplified depiction of the CNN architecture used in this study. The detailed architecture can be found in Can et al. (2019). The system components, their relationships and the technologies used for the development of each component are demonstrated in Figure 7.
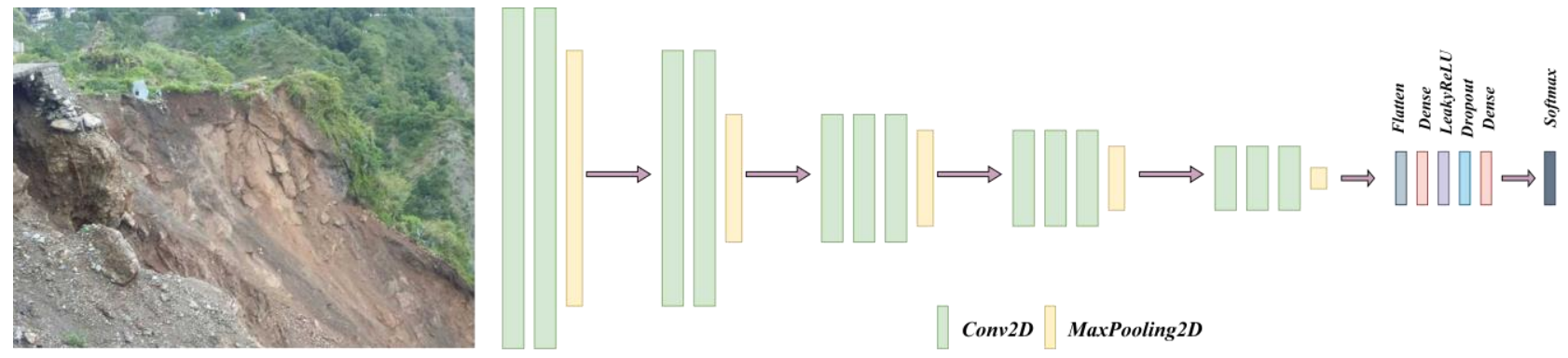

Figure 6. CNN architecture used for quality assessment (modified after Can et al., 2019).

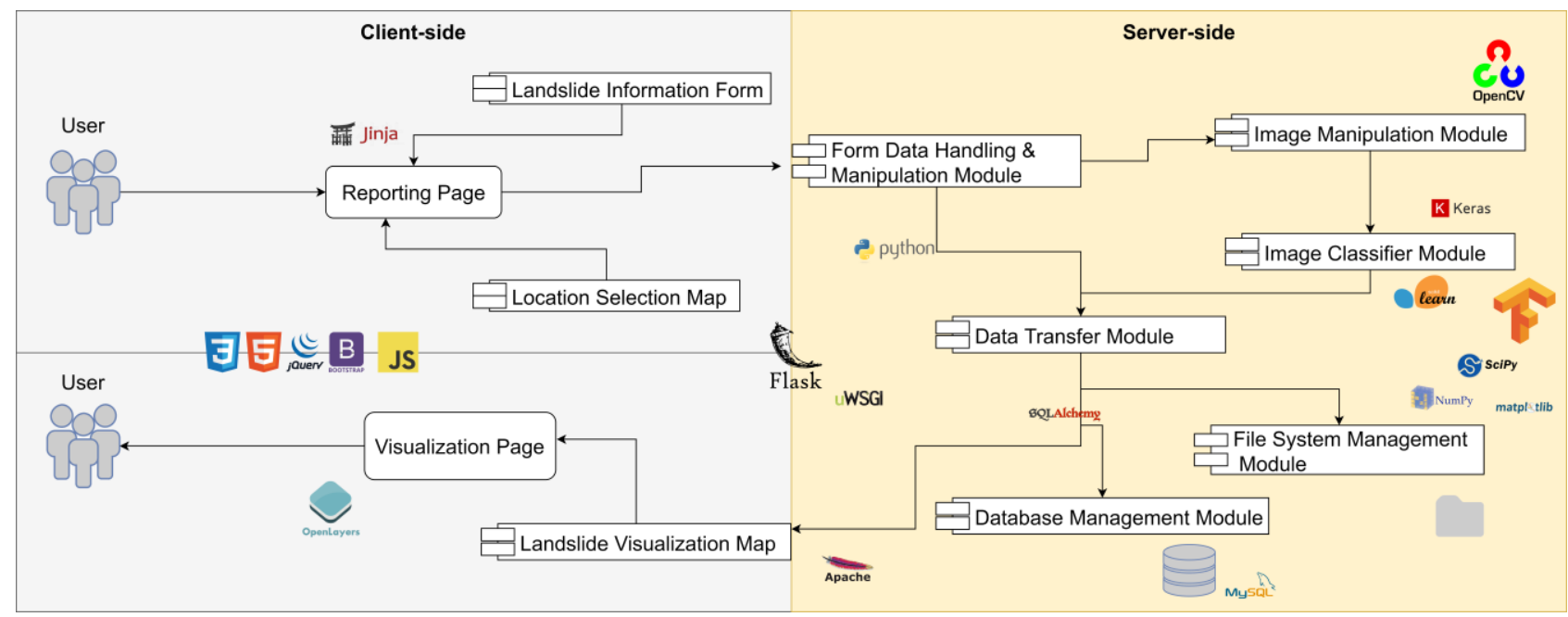

Figure 7. System components and their relationships, together with the technologies employed.

\section{RESULTS}

The developed CitSci platform employs several free and open source technologies, and in-house developed algorithms and tools for mobile- and web-based data collection, processing, quality assessment, analysis and visualisation. A decent level of flexibility, e.g. cross-platform compatibility for various operating systems, web browsers, mobile and web access, availability of location measurement capability, Internet accessibility, etc., is ensured with the developed system. The system can also be modified for other CitSci projects targeting geosciences.

In addition, the deep learning based image content fidelity inspection algorithm facilitates the automated operation of the system without manual intervention, and reduces the data load by eliminating the irrelevant data. Besides, the algorithm inherently analyses the decisions of inexperienced users on 
landslides and corrects (removes) if the decision was false (irrelevant).

Figures 8 and 9 were obtained from the demo application of the project page. Since the purpose of the demo page is ensuring the model's data quality assessment performance, all the posted data were stored and displayed on the map. Two different symbols are used on the web-map. If the posted image was classified as landslide, the map page represents the image with landslide symbol and locates the symbol to the provided location. If the image is classified as irrelevant, the image is represented with the red circle (Figure 8). By clicking on the symbol, the image can be shown in its original size. Figures 9 and 10 show examples from true and false landslide photographs provided by the users, which were classified correctly.

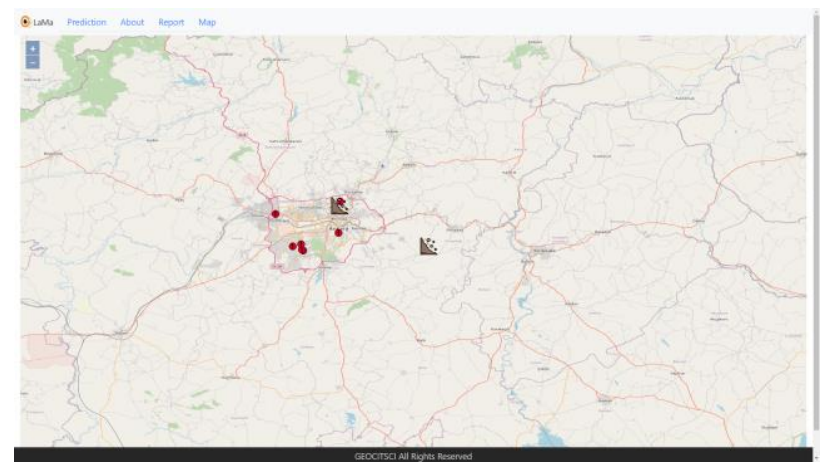

Figure 8. The symbols used on the demo application for landslide and non-landslide (red circles) data.
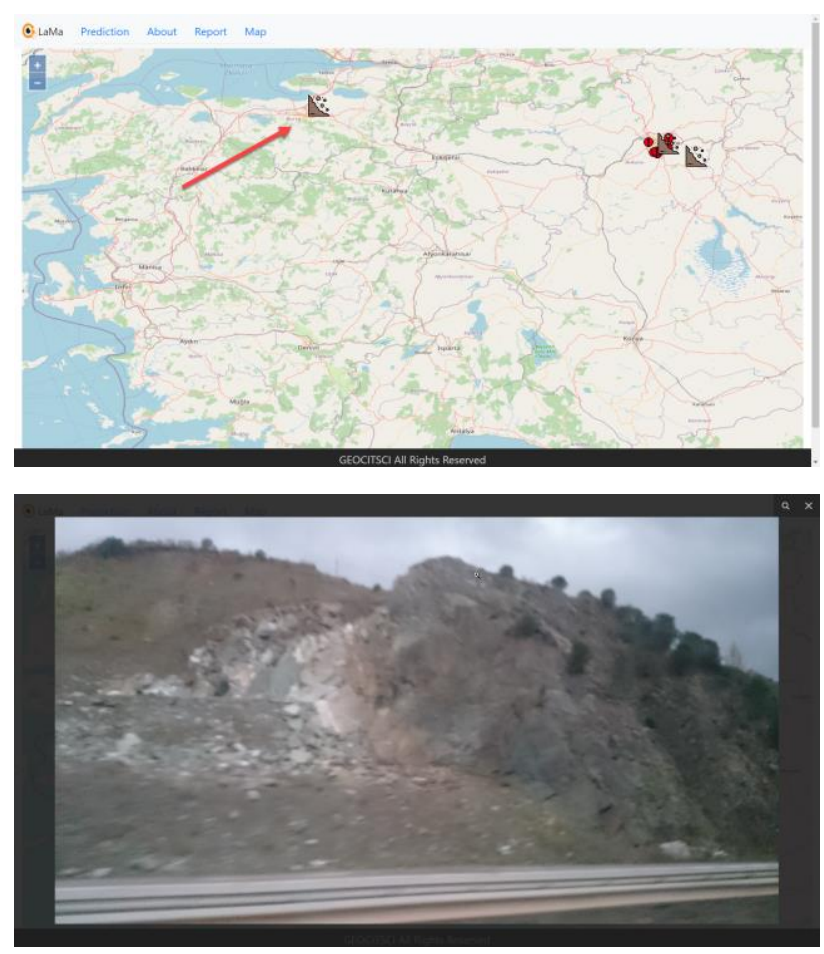

Figure 9. An example to the user-provided landslide photograph (below) together with its location (above). The photo was also classified as landslide in the image classifier.
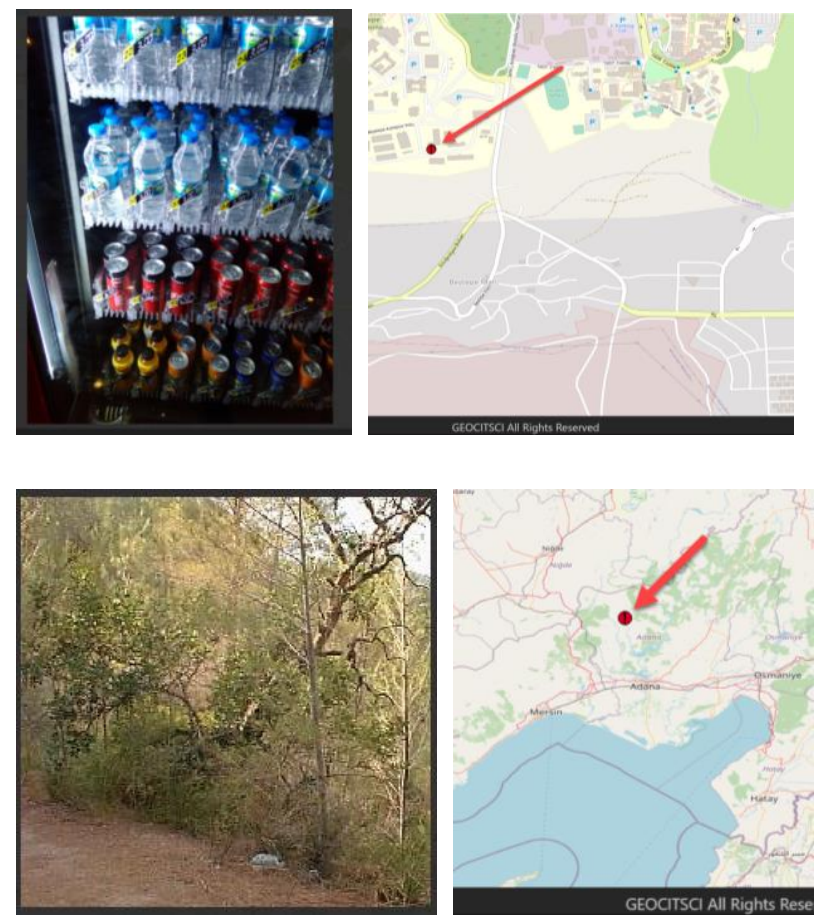

Figure 10. Examples to the user-provided photographs (left) together with their locations (right). The photos were classified as irrelevant in the image classifier.

\section{CONCLUSIONS AND FUTURE WORK}

Geospatial technologies have enormous potential to facilitate the CitSci studies related to the environment, ecosystem research and geoscience research. A system approach based on GIS ensures greater flexibility, data integrity, consistency and reliability. The emerging methods in $\mathrm{AI}$ and machine learning can also provide support to GIS for automated processing and analysis, and to increase the reliability through data quality assessment.

In this study, a flexible GIS-assisted CitSci platform, Geocitsci.com, has been developed by using different web and mobile technologies, spatial databases, statistical and image processing software libraries, and visualisation tools that are mostly free and open source. The developed system can assist the citizen scientists for textual and image data collection, also geolocated if the device has a location sensor, related to landslides, which is a commonly occurring natural hazard destructive for lives, infrastructure and economy. With the simple and flexible design of the data collection and visualisation tools, a user-friendly system could be achieved.

Data quality is often questionable in CitSci projects due to the motivation and background knowledge of the participants. The data quality assessment approach based on the in-house developed CNN image classifier module eliminates the data reliability issue of the collected landslide images largely. With the increase in the collected data in the repository, it is expected that the accuracy of the proposed method would also increase by training the model. 
Although the developed image classifier provides a great opportunity for image content analysis (i.e. landslide or not), further quality assessment procedures may be needed for other kinds of errors caused by misuse of the system. For example, a ground-truth comparison with respect to geomorphology or lithology may be useful for this purpose. In addition, the location data can be erroneous for different reasons, or the same photos can be sent multiple times, which results in redundant data in the system. Considering the fact that the error sources can be diverse and with different levels of severity, the solutions can be developed on demand when more data is collected. It needs to be emphasized that even though the error sources can be manifold, the geoinformation science has the potential to meet the demand of quality control with the recent developments in sensors (e.g. remote sensing, unmanned aerial vehicle photogrammetry, etc.), methods (i.e. feature extraction, change detection, semantic labelling, machine learning, etc.) and tools, which are openly available.

It is expected that with the increase in the volunteer contributions and the amount of the well-distributed data, a great contribution to landslide research and landslide hazard assessment can be made. As future work, we will concern about earthquake disaster mitigation and flood mapping by integrating suitable geospatial technologies and CitSci approaches to increase the public safety, reduce risks and economic losses.

\section{REFERENCES}

Bootstrap, 2020. https://getbootstrap.com/ (last accessed on 01.05.2020).

Brovelli, M.A., Ponti, M., Schade, S., Solis, P., 2020. Citizen Science in Support of Digital Earth. In: Manual of Digital Earth. Ed: Guo, H., Goodchild, M. F., \& Annoni, A., Springer, Singapore, 2020, pp. 593-622. Springer, Singapore. https://www.oapen.org/download?type=document $\&$ docid $=1006$ 981 (accessed on 01.05.2020)

Can, R., Kocaman, S., Gokceoglu, C., 2019. A Convolutional Neural Network Architecture for Auto-Detection of Landslide Photographs to Assess Citizen Science and Volunteered Geographic Information Data Quality. ISPRS International Journal of Geo-Information, 8(7), 300.

Chrisman, N.R., 1999. What Does 'GIS' Mean? Transactions in GIS, 3, 175-186.

Cochran, E. S., Lawrence, J. F., Christensen, C., Jakka, R., 2009. The Quake-Catcher Network: Citizen Science expanding seismic horizons. Seismol. Res. Lett. 80, 26-30.

Crall, A.W., Newman, G.J., Jarnevich, C.S., Stohlgren, T.J., Waller, D.M., Graham, J., 2010. Improving and integrating data on invasive species collected by citizen scientists. Biological Invasions, 12, 3419-3428.

CSA, 2020. Citizen Science Association. http://www.citizenscience.org (last accessed on 02.05.2020)

Cutter S.L., Ismail-Zadeh, A., Alcantara-Ayala, I., Altan, O., Baker, D.N., Briceño, S., Gupta, H., Holloway, A., Johnston,
D., McBean G.A., Ogawa, Y., Paton, D., Porio, E., Silbereisen, R.K., Takeuchi, K., Valsecchi, G.B., Vogel, C. And $\mathrm{Wu}$, G., 2015. Global risks: Pool knowledge to stem losses from disasters. Nature, 522, 277-279. doi:10.1038/522277a

De Longueville, B., Luraschi, G., Smits, P., Peedell, S., and De Groeve, T. 2010. Citizens as sensors for natural hazards: a VGI integration workflow. Geomatica 64(1):41-59.

Flask, 2020. https://flask.palletsprojects.com/en/1.1.x/ (last accessed on 01.05.2020).

Holderness, T., Turpin, E., 2017. PetaJakarta.org: Assessing the Role of Social Media for Civic Co-Management During Monsoon Flooding in Jakarta, Indonesia. White Paper. SMART Infrastructure Facility, University of Wollongong ISBN: 978-1- 74128-249-8)

Jinja2, 2020. Jinja2 Project Description. https://pypi.org/project/Jinja2/ (last accessed on 01.05.2020).

Juang, C. S., Stanley, T. A., Kirschbaum, D. B., 2019. Using citizen science to expand the global map of landslides: Introducing the Cooperative Open Online Landslide Repository (COOLR). PloS one, 14(7).

Kocaman, S., Anbaroglu, B., Gokceoglu, C., Altan, O., 2018. A Review on Citizen Science (CitSci) Applications For Disaster Management. Int. Arch. Photogramm. Remote Sens. Spatial Inf. Sci. 2018, XLII-3/W4, 301-306, doi:10.5194/isprsarchives-XLII-3-W4-301-2018.

Kocaman, S., Gokceoglu, C., 2018. On the use of CitSci and VGI in Natural Hazard Assessment. International Archives of the Photogrammetry, Remote Sensing \& Spatial Information Sciences 2018. Volume XLII-5, ISPRS TC V Mid-term Symposium "Geospatial Technology - Pixel to People", 20-23 November 2018, Dehradun, India.

Kocaman, S. Gokceoglu, C., 2019a. A CitSci app for landslide data collection. Landslides $16,611$. https://doi.org/10.1007/s10346-018-1101-2.

Kocaman S., Gokceoglu, C., 2019b. CitSci as a new approach for landslide researches. In Intelligent Systems for Crisis Management Altan, O., Chandra, M., Sunar, F., Tanzi, T.J. (Eds.) Lecture Notes in Geoinformation and Cartography, Springer, Cham, pp. 161-183. ISBN 978-3-030-05330-7

Liang, W.T., Lee, J.C., Chen, K.H., Hsiao, N.C., 2017. Citizen earthquake science in Taiwan: From science to Hazard mitigation. Journal of Disaster Research, 12(6), 1174-1181. doi: 10.20965/jdr.2017.p1174

Microsoft, 2020. Bing Maps APIs https://www.microsoft.com/en-us/maps/choose-your-bingmaps-api (last accessed on 01.05.2020).

NASA, $2020 . \quad$ Landslide Reporter. https://www.nasa.gov/solve/landslide_reporter/ (last accessed on 01.05.2020). 
Nolasco-Javier, D., Kumar, L., 2018. Deriving the rainfall threshold for shallow landslide early warning during tropical cyclones: a case study in northern Philippines. Natural Hazards 90 (2): 921-941. https://doi.org/10.1007/s11069-017-3081-2

OpenLayers, 2020. https://openlayers.org/ (last accessed on 01.05.2020).

Schade, S., Díaz, L., Ostermann, F., Spinsanti, L., Luraschi, G., Cox, S., Nuñez, M., De Longueville, B., 2013. Citizenbased sensing of crisis events: sensor web enablement for volunteered geographic information. Applied Geomatics, 5(1), 3-18

Yalcin, I., Kocaman, S., Gokceoglu, C., 2020a. A CitSci Approach for Rapid Earthquake Intensity Mapping: A Case Study from Istanbul (Turkey). ISPRS International Journal of Geo-Information, 9, 266. doi.org/10.3390/ijgi9040266

Yalcin, I., Kocaman, S., Gokceoglu, C., 2020b. Production of Iso-Intensity Map for the Elazig Earthquake (Jan 24, 2020) Using Citizen Collected Geodata. ISPRS Congress 2020 (accepted for publication). 